\title{
Evde Yaşayan Yaşlılarda Yalnızlık, Yaşam Doyumu ve Ölüm Kaygısının Belirlenmesi
}

Prof. Dr. Havva Tel ${ }^{1}$

Dr. Öğr. Üyesi Medine Koç²*

Prof. Dr. Hatice Tel Aydın ${ }^{3}$

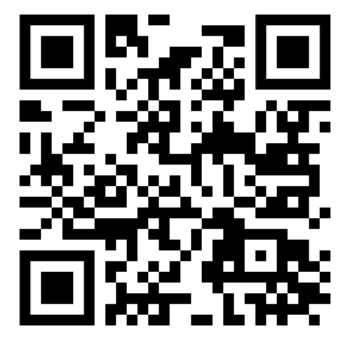

Geliş tarihi: 29.06.2020

Kabul tarihi: 19.08.2020

\section{Atıf bilgisi:}

IBAD Sosyal Bilimler Dergisi Sayı: Özel Sayı Sayfa: 1-10 Yıl: 2020

This article was checked by Turnitin. Similarity Index $26 \%$

Bu makalede araştırma ve yayın etiğine uyulmuştur.

${ }^{1}$ Sivas Cumhuriyet Üniversitesi, Türkiye, havvatel@yahoo.com,

ORCID ID 0000000191712115

${ }^{2}$ Tokat Gaziosmanpaşa Üniversitesi, Türkiye, $\quad$ kocmedine@gmail.com, ORCID ID 0000000192988885

${ }^{3}$ Sivas Cumhuriyet Üniversitesi, Türkiye, haticetel@gmail.com,

ORCID ID 0000000215188080
ÖZ

Araştırma evde yaşayan yaşlı bireylerde yalnızlık, yaşam doyumu ve ölüm kaygısını belirlemek amacı ile yapılmıştır. Tanımlayıcı tipteki bu araştırmanın örneklemini 27 Mayıs - 27 Haziran 2016 tarihleri arasında bir aile sağlığı merkezine kayıtlı, evde yaşayan 65 yaş ve üzeri 545 birey oluşturmuştur. Araştırma verileri yaşlı bilgi formu, yaşlılar için yalnızlık ölçeği, yaşam doyumu ölçeği ve ölüm kaygısı ölçeği kullanılarak toplanmıștır. Çalışmaya katılan yaşlı bireylerin yaş ortalaması $72.95 \pm$ 6.18 olup, \%53.0'ü erkek, \%56.7'si evli, \%33.9'u okur-yazar, \%51.6's1 eşi ile birlikte yaşamaktadır. Yaşılı bireylerde medeni durum, eğitim durumu ve birlikte yaşadığı kişiye göre yalnızlık, yaşam doyumu ve ölüm kaygısı puanları arasında istatistiksel olarak anlamlı bir fark olduğu saptanmıştır $(p<0.05)$. Yaşlılarda yalnızlık ile yaşam doyumu arasında anlamlı pozitif yönde zayıf ilişki $(r=.272, p=.000)$, ölüm kaygısı ile yalnızlık arasında anlamlı negatif yönde orta düzeyde ilişki $(\mathrm{r}=-.408$, $\mathrm{p}=.000$ ), ölüm kaygısı yaşam doyumu arasında anlamlı negatif yönde zayıf bir ilișki $(\mathrm{r}=-.319, \mathrm{p}=.000)$ saptanmıştır. Ailesi olmayan yaşlılarda yalnızlık ve yaşam doyumu puanı daha yüksek, ölüm kaygısı puanı daha düşüktür. Yaşlı bireylerin çevresi ile etkileşiminin artırılması, aktif ve üretken bir yaşam sürmesinin desteklenmesi, psikososyal yönden değerlendirilerek uygun destek ve danışmanlığın sağlanması önerilmektedir.

Anahtar Kelimeler: Yaşlı, Yaşam Doyumu, Yalnızlık, Ölüm Kaygısı 
Determination of Loneliness, Life Satisfaction and Death Anxiety in Elderly Living at Home

Prof. Dr. Havva Tel ${ }^{1}$

Assist. Prof. Dr. Medine Koç ${ }^{2 *}$

Prof. Dr. Hatice Tel Aydın ${ }^{3}$

First received: 29.06 .2020

Accepted: 19.08 .2020

\section{Citation:}

IBAD Journal of Social Sciences

Issue: Special Issue Pages: 1-10

Year: 2020

This article was checked by Turnitin. Similarity Index $26 \%$

${ }^{1}$ Sivas Cumhuriyet Universitiy, Turkey, havvatel@,yahoo.com,

\section{ORCID ID 0000000191712115}

${ }^{2}$ Tokat Gaziosmanpaşa Universitiy, Turkey, $\quad$ kocmedine@gmail.com, ORCID ID 0000000192988885

${ }^{3}$ Sivas Cumhuriyet Universitiy, Turkey, haticetel@gmail.com,

ORCID ID 0000000215188080

* Corresponding Author

\begin{abstract}
The research was carried out to determine loneliness, life satisfaction and death anxiety in elderly individuals living at home. This sample of this descriptive study consisted of 545 individuals aged 65 and over who were registered at a family health center between 27 May - 27 June 2016 and who lived at home. The research data were collected using the elderly in formation form, loneliness scale for elderly, life satisfaction scale and death anxiety scale. The average age of the elderly individuals participating in the study is $72.95 \pm 6.18,53.0 \%$ are male, $56.7 \%$ are married, $33.9 \%$ are literate, $51.6 \%$ are living with their spouse. A statistically significant different was found between marital status, education level and loneliness, life satisfaction and death anxiety scores in elderly individual $(p<0.05)$. There were significant positive weak correlatin between loneliness and satisfaction $(\mathrm{r}=.272, \mathrm{p}=.000)$, moderately negative relatioship between death anxiety and loneliness $(\mathrm{r}=-.408$, $\mathrm{p}=.000)$ in elderly. There was significant negative correlation between death anxiety and life satisfaction $(\mathrm{r}=-.319, \mathrm{p}=.000)$ in elderly. There is a relationship between loneliness, life satisfaction and death anxiety in elderly people. It is recommended to increase the interaction of the elderly with their environment, to support an active and productive life, to provide appropriate support and counseling by evaluating in terms of psychosocial aspects.
\end{abstract}

Keywords: Elderly, Life Saticfaction, Loneliness, Death Anxiety 


\section{GİRIŞ}

Günümüzde tüm dünyada olduğu gibi Türkiye'de de yaşlı nüfus diğer yaş gruplarındaki nüfusa göre daha yüksek bir hız ile artmaktadır. Türkiye İstatistik Kurumu (TÜIK) verilerine göre 2014 yılında \%8 olan yaşlı nüfus oranı 2019 yılında \%9.1'e yükselmiştir. Yaşlı nüfus oranının 2023 yılında \%10.2, 2040 yılında \%16.3 olacağı tahmin edilmektedir (TÜiK, 2018; TÜIK, 2019). Yaşam döngüsünün son aşaması olan yaşlılık fiziksel ve bilişsel fonksiyonlarda gerileme, sağlı̆̆ı, üretkenliğin, rol ve statünün, bağımsızlı̆̆ın kaybı, eş, akran kaybı gibi birç̧ok kaybın yaşandığı, yakın ilişkilerin, sosyal yaşantının ve sosyal desteğin azaldığı bir dönemdir (Parlar Kılıç, Karadağ, Koçak ve Korhan, 2014; Ağırman, Gençer, Arıca, Kaya ve Eğici, 2017; Çam, Atay ve Işık, 2018; Şimşek, Küçük Öztürk ve Yüceler Kaçmaz, 2018). Toplumsal gelişme ve değişmeler sonunda aile yapısının çekirdek aileye dönüşmesi ve aile üyelerinin çalışma yaşamına girmesi ile yalnız yaşayan yaşlı sayısı giderek artmakta, yaşlıların sosyal etkileşimleri azalmaktadır (Erol, Sezer, Şişman ve Öztürk, 2016; Ağırman vd., 2017). Sosyal ilişki ve etkileșimlerin azalması bireyin yaşamını olumsuz etkileyerek yalnızlık duygusuna neden olmaktadır. Yalnızlık duygusu bireyin yaşamının amaçsız ve gereksiz olduğunu düşünmesine, boşluk, kimsesizlik ve terk edilmişlik duygusu yaşamasına yol açabilmektedir (Erol vd., 2016). Aynı zamanda yalnızlık sosyal ilişkilerin arzu edilenden daha az veya sınırlı olması, yoksunluk ve yetersizlikten kaynaklanan, bireyleri pek memnun etmeyen bir durumdur (Çam vd., 2018; Şimşek vd., 2018). Yaşl1lık döneminde görülen duyu kayıplarının oluşturduğu sağlık sorunları, sosyal destek yetersizliği, sosyal etkileşimin azalması veya yokluğu, yalnız yaşama gibi durumlarla yaşlılarda yalnızlığın arttığı belirtilmiştir (Çevik Akyıl, Adıbelli, Erdem, Kırăg, Aktaş ve Karadakovan, 2018; Şimşek vd., 2018). Yapılan çalışmalarda; Genç ve Dalkılıç (2013) 108 yaşııııı \%55.6'sının yalnızlık yaşadığını, Erol vd. (2016) kentte yaşayan yaşlıların yalnızlık puanının köyde yaşayan yaşlıların yalnızlık puanından daha yüksek olduğunu saptamıştır. Yaşlıların yaşadığı yalnızlık duygusunun yaşam doyumunu olumsuz etkilediği belirtilmektedir. Bireyin yaşama dair beklentileri ve bunları karşılanma düzeyleri ile ortaya çıkan durum olan yaşam doyumu bireyin ruhsal ve fiziksel iyilik hali, sosyal ilişkiler, ekonomik güç ve güvende olma gibi faktörlerden olumlu etkilenmektedir (Recepoğlu, 2013; Erol vd., 2016). Yaşlılık dönemine kadar kendi ihtiyaçlarını karşılayıp toplum için üretken bir konumda olan birey yaşlılıkta giderek tüketen ve yardım ihtiyacı artan birey durumuna gelebilmekte ve yaşam doyumu da azalabilmektedir (Başterzi ve Ertekin Yalçın, 2005). Yaşlı bireylerin algıladıkları sosyal destek düzeyinin yaşam doyumuna etkisinin araştıııldığ 1 ve 516 yaşlı ile yapılan bir çalışmada fiziksel sağlık durumu ile yaşam doyumu arasında negatif yönlü anlamlı ilişki olduğu saptanmıştır (Boylu Aydıner ve Günay, 2018).

Yaşlılık döneminde ortaya çıkan birçok değişiklik ve kronik hastalıklar, fizik gücün azalması nedeni ile birey kendini ölüme daha yakın hissetmektedir (Üstüner Top, Saraç ve Yaşar, 2010). Karahan ve Hamarta (2019) kronik hastalığı olan yaşlılarda ölüm kaygısının daha yüksek olduğunu tespit etmiştir. Ölüm kaygısı, birey ölüm tehdidi altında olduğunda tetiklenebilecek bir savunma mekanizmasından kaynaklanan bilinçli veya bilinçsiz bir psikolojik durum olup bireyin artık var olmayacağının, kendisini ve dünyayı kaybedebileceğinin, bir hiç olabileceğinin farkındalığı sonrası gelişir (Üstüner Top vd., 2010; Zhang, Peng, Gao, Huang, Cao, Zheng ve Miao, 2019). Ölüm kaygısı çoğunlukla bireyler üzerinde olumsuz etkilere sahiptir. Bazı yaşlıların bu süreci kabullenerek huzurlu ölümü beklediği görülürken; bazı yaşlıların kabullenmeyerek rahatsızlık duyduğu görülmektedir (Sayın Kasar, Karaman, Say Şahin, Yıldırım ve Şenuzun Aykar, 2016). Yoğun ölüm kaygısı yaşayan yaşlıların yaşamdan doyum almadığı ve bu dönemi mutsuz ve yalnız geçirdikleri belirtilmektedir (Engin, Uğuryol ve Kaçmaz, 2016).

Literatürde yaşlı bireylerde yalnızlık, yaşam doyumu ve ölüm kaygısı ile ilgili ayrı ayrı veya bu değişkenlerin ikili olarak araştırıldığ ç̧alışmalar olmasına karşın yaşlılarda yalnızlık, yaşam doyumu ve ölüm kaygısını birlikte ele alan bir çalışmaya rastlanılmamıştır. Gelişimsel bir kriz dönemi olan yaşl11ıkta; bireyin yaşlılık dönemi sorunları ile etkin baş edebilmesi, sağlığının korunması ve sürdürülmesi, yaşam kalitesi ve yaşam doyumunun artırılması için yalnızlı, yaşam doyumu ve ölüm kaygısı gibi sağlığın psikososyal belirleyicilerinin değerlendirilmesi, bireyin benlik algısının güçlendirilmesi önemlidir. Tanımlayıcı tipteki bu araştırma 65 yaş ve üzeri evde yaşayan yaşlı bireylerde yalnızlık, yaşam doyumu ve ölüm kaygısını belirlemek amacı ile yapılmıştır. 


\section{GEREÇ VE YÖNTEM}

\section{Araştırmanın tipi, yeri ve zamanı}

Araştırma evde yaşayan 65 yaş ve üzeri bireylerde yalnızlık, yaşam doyumu ve ölüm kaygısını belirlemek amacı ile yapılmıştır. Tanımlayıcı tipteki bu araştırma bir aile sağlığı merkezi bölgesinde yaşayan ve 27 Mayıs - 27 Haziran 2016 tarihleri arasında çalışmaya katılmayı kabul eden 545 yaşlı birey ile yapilmıştır.

Araştırmanın evreni ve örneklemi: Araştırmanın evrenini il merkezinde bir aile sağlığı merkezine kayıtlı, 65 yaş ve üzeri evde yaşayan bireyler, örneklemini 27 Mayıs - 27 Haziran 2016 tarihleri arasında bir aile sağlığı merkezine kayıtlı, evde yaşayan ve çalışmaya katılmayı kabul eden 545 yaşlı birey oluşturmuştur.

\section{Veri toplama araçları ve uygulama}

Araştırma verileri yaşlı bilgi formu, yaşlılar için yalnızlık ölçeği, yaşam doyumu ölçeği ve ölüm kaygısı ölçeği kullanılarak yüz-yüze görüşme yoluyla toplanmıştır.

Yaşı Bilgi Formu: Yaşlı bireylerin sosyo-demografik özelliklerini sorgulamaya yönelik soruları içermektedir.

Yaşlılar İçin Yalnızlık Ölçeği (YYÖ): 1985 yılında de Jong Gierveld ve Kamphuis tarafindan geliştirilmiştir. Ölçeğin Türkçe geçerlik güvenirlik çalışması 2015 yılında Akgül ve Yeşilyaprak tarafindan yapılmıştır. Yalnızlık duygusunu ölçmek amacıyla geliştirilen ölçek üçlü likert tipi 11 madde içermektedir. Ölçeğin duygusal yalnızlık $(2,3,5,6,9,10)$ ve sosyal yalnızlık $(1,4,7,8,11)$ olmak üzere iki alt boyutu bulunmaktadır. Bu iki boyutun toplamı genel yalnızlık puanını oluşturmaktadır. Ölçekte olumlu yöndeki ifadeleri içeren maddeler $(1,4,7,8,11) \quad 0=$ evet, $1=$ olabilir, $2=$ hayır, olumsuz yöndeki ifadeleri içeren maddeler $(2,3,5,6,9,10) 2=$ evet, $1=$ olabilir, $0=$ hayır şeklinde puanlanmaktadır. Ölçekten alınacak en düşük puan 0 , en yüksek puan 22 'dir. Ölçekten alınan puan yükseldikçe, bireyin yalnızlık düzeyinin de yüksek olduğu kabul edilmektedir. Ayrıca ölçekten elde edilen toplam puan; 0-4 puan yalnız değil / yalnızlık hissetmiyor, 5-14 puan kabul edilebilir yalnızlık, 15-18 puan çok yalnız, 19-22 puan çok yoğun yalnızlık olarak gruplandırılabilmektedir (de Jong Gierveld ve Kamphuis 1985; Akgül ve Yeşilyaprak, 2015).

Yaşam Doyumu Ölçeği (YDÖ): 1985 yılında Diener, Emmons ve Griffin tarafindan geliştirilmiştir. Ölçeğin Türkçe geçerlik, güvenirlik çalışması 1991 yılında Köker ve 1993 yılında Yetim tarafından yapılmıştır. Bireylerin yaşamlarından aldıkları doyumu belirlemek amacıyla geliştirilen ölçek yedili likert tipte (kesinlikle katılmıyorum=1 puan, kesinlikle katılıyorum=7 puan) beş maddeden oluşmaktadır. Yaşam Doyumu Ölçeğinden alınabilecek en düşük puan 5, en yüksek puan 35'tir. Ölçekten alınan puanın düşük olması yaşam doyumunun düşük olduğunu gösterir (Diener vd.,1985; Yetim, 1993).

Ölüm KaygıSı Ölçeği (ÖKÖ): 1970 yılında Templer tarafindan geliştirilmiştir. Ölçeğin Türkçe’ye uyarlaması Şenol (1989) tarafından yapılmıştır. 15 madde içeren ölçek bireyin kendi ölümü ve ölüm riski ile ilgili kaygı ve korkuları değerlendirmektedir. Ölçek maddeleri doğru-yanlış seklinde yanıtlanmaktadır. Ölçekteki ilk 9 maddeye verilen her bir "evet" yanıtı için "1", "hayır" yanıtı için " 0 ", diğer 6 maddeye verilen her bir "hayır" yanıtı için "1", "evet" yanıtı için ise "0" puandır. Ölçekten alınabilecek en yüksek puan 15'tir. Ölçekten elde edilen 0-4 puan "hafif düzeyde", 5-9 puan "orta düzeyde", 10-14 puan "ağır düzeyde", 15 puan "panik düzeyde" ölüm kaygısı olarak değerlendirilir (Templer, 1970; Şenol, 1989).

\section{Verilerin toplanması ve analizi}

Etik yönü ile araştırma Helsinki Deklerasyonu Prensipleri'ne uygun şekilde yürütülmüştür. Araştırma için yazılı kurumsal izin alındıktan sonra (Sayı:1433965-020), yaşlı bireylere araştırmanın amacı, yararları açıklanmış, gönüllülük ilkesine dikkat edilerek bilgilendirilmiş onamları alınmıştır. Veri toplama araçları yüz-yüze görüşme yoluyla uygulanmıştır.

Araştırmadan elde edilen verilerin analizi 22.0 SPSS istatistik paket programı kullanılarak yapılmıştır. Verilerin değerlendirilmesinde yüzdelik dağılım, ortalama, $t$ testi ve tek yönlü varyans analizi testi ile Pearson korelasyon analizi kullanılmıştır. 


\section{BULGULAR}

Çalışmaya katılan yaşlı bireylerin yaşları 65-90 arasında değişmekte ortalama $72.95 \pm 6.18$ 'dir. Yalnızlık ölçek puanı 0-22 arasında değişmekte ortalama $8.01 \pm 3.77$ puan olarak kabul edilebilir yalnızlık düzeyindedir. Yaşam doyumu puanı 5-35 arasında değişmekte ortalama 15.81 \pm 7.22'dir. Ölüm kaygıs1 puanı 5-15 arasında değişmekte ortalama $9.28 \pm 1.67$ puan olarak orta düzeydedir. Yaşlılarda yalnızlık ile yaşam doyumu arasında anlamlı pozitif yönde zayıf ilişki $(\mathrm{r}=.272, \mathrm{p}=.000)$, ölüm kaygısı ile yalnızlık arasında anlamlı negatif yönde orta düzeyde ilişki $(\mathrm{r}=-.408, \mathrm{p}=.000)$, ölüm kaygısı yaşam doyumu arasında anlamlı negatif yönde zayıf bir ilişki $(\mathrm{r}=-.319, \mathrm{p}=.000)$ olduğu saptanmıştır.

Tablo 1. Yaşlı bireylerin tanıtıcı özellikleri

\begin{tabular}{|l|rr|}
\hline Tanıtıcı Özellikler & Sayı & \% \\
\hline Cinsiyet & & \\
\hline Kadın & 256 & 47.0 \\
Erkek & 289 & 53.0 \\
\hline Medeni durum & & \\
\hline Bekar & 31 & 5.7 \\
Evli & 309 & 56.7 \\
Dul & 189 & 34.7 \\
Boşanmış & 16 & 2.9 \\
\hline Eğitim & & \\
\hline Okur-yazar değil & 140 & 25.7 \\
Okur yazar & 185 & 33.9 \\
İlkokul & 134 & 24.6 \\
Ortaokul & 53 & 9.7 \\
Lise & 33 & 6.1 \\
\hline Birlikte yaşadı̆̆ kişiler & & \\
\hline Eş & 281 & 51.6 \\
Çocuklar & 153 & 28.1 \\
Yakın akraba & 65 & 11.9 \\
Yalnız yaşıyor & 46 & 8.4 \\
\hline
\end{tabular}

Tablo 1'de yaşlı bireylerin tanıtıcı özellikleri görülmektedir. Yaşlı bireylerin \%53.0'ünün erkek, \%56.7'sinin evli, \%33.9'unun okur-yazar, \%51.6'sının eşi ile birlikte yaşadığı saptanmıştır.

Tablo 2. Yaşlıların medeni duruma göre yalnızlık, yaşam doyumu ve ölüm kaygısı puanları

\begin{tabular}{|l|l|l|l|}
\hline & Yalnızlık & Yaşam doyumu & Ölüm kaygısı \\
\hline Medeni durum & $\boldsymbol{X} \pm \mathbf{S S}$ & $\boldsymbol{X} \pm \mathbf{S S}$ & $\boldsymbol{X} \pm \mathbf{S S}$ \\
\hline Bekar & $9.96 \pm 2.41$ & $17.4 \pm 7.22$ & $8.38 \pm 1.66$ \\
Evli & $7.95 \pm 4.13$ & $15.48 \pm 7.34$ & $9.30 \pm 1.62$ \\
Dul & $7.56 \pm 3.24$ & $15.6 \pm 7.10$ & $9.48 \pm 1.70$ \\
Boşanmış & $10.2 \pm 1.96$ & $19.50 \pm 5.01$ & $8.18 \pm 1.37$ \\
& $\mathrm{~F}=6.420$ & $\mathrm{~F}=4.220$ & $\mathrm{~F}=6.364$ \\
& $\mathrm{p}=.000$ & $\mathrm{p}=.051$ & $\mathrm{p}=.000$ \\
\hline
\end{tabular}

Tablo 2'de yaşlıların medeni duruma göre yalnızlık, yaşam doyumu ve ölüm korkusu puanları görülmektedir. Yaşlıların medeni duruma göre yalnızlık, yaşam doyumu ve ölüm kaygısı puanları arasında istatistiksel olarak anlamlı fark olduğu saptanmıştır $(\mathrm{p}<0.05)$. Boşanmış yaşlılarda yalnızlık puanı ve yaşam doyumu puanı daha yüksek, ölüm kaygısı puanı daha düşüktür. 
Tablo 3. Yaşlıların eğitim durumuna göre yalnızlık, yaşam doyumu ve ölüm kaygısı puanları

\begin{tabular}{|l|l|l|l|}
\hline & Yalnızlık & Yaşam doyumu & Ölüm kaygısı \\
\hline Eğitim & $\boldsymbol{X} \pm$ SS & $\boldsymbol{X} \pm$ SS & $\boldsymbol{X} \pm \mathbf{S S}$ \\
\hline Okur-yazar değil & $7.71 \pm 4.39$ & $15.35 \pm 7.30$ & $9.09 \pm 1.76$ \\
Okur yazar & $7.47 \pm 3.28$ & $16.27 \pm 7.35$ & $9.62 \pm 1.60$ \\
İlkokul & $8.72 \pm 3.75$ & $16.19 \pm 7.00$ & $9.33 \pm 1.70$ \\
Ortaokul & $8.09 \pm 3.59$ & $14.49 \pm 6.82$ & $8.87 \pm 1.70$ \\
Lise & $9.30 \pm 3.30$ & $16.60 \pm 7.67$ & $\mathrm{~F}=3.299$ \\
& $\mathrm{~F}=3.385$ & $\mathrm{~F}=.861$ & $\mathrm{p}=.011$ \\
& $\mathrm{p}=.009$ & $\mathrm{p}=.487$ & \\
\hline
\end{tabular}

Tablo 3'de yaşlıların eğitim durumuna göre yalnızlık, yaşam doyumu ve ölüm kaygısı puanları görülmektedir. Yaşlıların eğitim durumuna göre yalnızlık ve ölüm kaygısı puanları arasında istatistiksel olarak anlamlı fark olduğu saptanmıştır $(\mathrm{p}<0.05)$. Lise ve üzeri eğitimli yaşlılarda yalnızlık puanı daha yüksek, ölüm kaygısı puanı daha düşüktür.

Tablo 4. Yaşlıların birlikte yaşadığı kişilere göre yalnızlık, yaşam doyumu ve ölüm kaygısı puanları

\begin{tabular}{|l|l|l|l|}
\hline & Yalnızlık & Yaşam doyumu & Ölüm korkusu puanı \\
\hline Birlikte yaşadığı kişiler & Ort \pm SS & Ort \pm SS & Ort \pm SS \\
\hline Eş & $7.74 \pm 4.15$ & $14.82 \pm 7.33$ & $9.47 \pm 1.59$ \\
Çocuklar & $7.58 \pm 3.18$ & $16.19 \pm 6.66$ & $9.49 \pm 1.56$ \\
Yakıı akraba & $10.37 \pm 2.73$ & $20.00 \pm 6.57$ & $8.20 \pm 1.74$ \\
Yalnız yaşıyor & $8.39 \pm 3.28$ & $14.65 \pm 7.24$ & $8.82 \pm 1.98$ \\
& $\mathrm{~F}=5.631$ & $\mathrm{~F}=7.622$ & $\mathrm{~F}=8.800$ \\
& $\mathrm{p}=.000$ & $\mathrm{p}=.000$ & $\mathrm{p}=.000$ \\
\hline
\end{tabular}

Tablo 4'te yaşlıların birlikte yaşadığı kişilere göre yalnızlık, yaşam doyumu ve ölüm kaygısı puanları görülmektedir. Yaşlıların birlikte yaşadığı kişilere göre yalnızlık, yaşam doyumu ve ölüm kaygısı puanları arasında istatistiksel olarak anlamlı fark olduğu saptanmıştır $(p<0.05)$. Yakın akraba ile yaşayanlarda yalnızlık puanı ve yaşam doyumu puanı daha yüksek, ölüm kaygısı puanı daha düşüktür.

Yaşlılarda yalnızlık ile yaşam doyumu arasında anlamlı pozitif yönde zayıf ilişki $(r=.272, p=.000)$, ölüm kaygısı ile yalnızlık arasında anlamlı negatif yönde orta düzeyde ilişki $(\mathrm{r}=-.408, \mathrm{p}=.000)$, ölüm kaygısı yaşam doyumu arasında anlamlı negatif yönde zayıf bir ilişki $(\mathrm{r}=-.319, \mathrm{p}=.000)$ saptanmıştır.

\section{TARTIŞMA}

Sağlıklı yaşlanma fiziksel sağlığın sürdürülmesi kadar ruh sağlığının korunmasını ve kişilerarası ilişkilerin etkin sürdürülmesini gerektirmektedir. Yaşlı bireylerde yaşla birlikte artan fiziksel, sosyal, psikolojik, ekonomik ve bazı çevresel değişiklikler, kronik sağlık sorunları, fiziksel aktivitede azalma, sağlık algısında bozulma yaşamdan doyumun azalmasına ve yalnızlığın artmasına neden olmaktadır (Meléndez, Tomás, Oliver ve Navarro, 2009; Rowe ve Kahn, 2015). Yaşlılarda yalnızlığın sık görüldüğü ve yaşlılarda yalnızlık prevalansının \%40 olduğu belirtilmektedir (Khademi, Rashedi, Sajadi ve Gheshlaghi, 2015). Yalnızlık yaşlının iyilik halini ve yaşamdan aldığı doyumu etkileyebilmektedir. Yaşlılarda yalnızlık, yaşam doyumu ve ölüm kaygısının belirlenmesi amacıyla yapılan bu çalışmada; yaşlıların kabul edilebilir düzeyde yalnızlık, düşük düzeyde yaşam doyumu, orta düzeyde ölüm kaygısı yaşadığı, yaşlılarda yalnızlık arttıkça yaşam doyumunun da arttığı saptanmıştır. Literatürde yalnızlığın yaşam doyumunu olumsuz etkileyen bir faktör olduğu belirtilmektedir (Erol vd., 2016; Kapıkıran, 2016). Bu çalışmadaki evde yaşayan yaşlılarda yalnızlık arttıkça yaşam doyumunun da artması sonucunun; yaşlıların günlük yaşam aktivitelerini sürdürmesine firsat veren ev ortamında, tanıdık çevrede, güvendiği insanlarla birlikte yaşaması ve benlik bütünlüğü ile ilişkili olduğu, bu nedenle yalnızlığın artmasının yaşlıların yaşam doyumunu olumsuz etkilemediği düşünülmektedir. Bununla birlikte yaşlı bireylerde yalnızlık ve yaşam doyumunun araştırıldığı birçok çalışmada farklı sonuçlar olduğu görülmektedir. Özer (2001) huzurevinde yaşayan yaşlı bireyler ve aile ortamında yaşayan yaşlı bireyler ile yaptı̆̆ çalışmada yaşam doyumu ölçeği puanı ortalamasını huzurevinde yaşayanlarda 9.07 puan, aile ortamında yaşayanlarda 11.98 puan olarak, Softa, Karaahmetoğlu, Erdoğan ve Yavuz (2015) huzurevinde kalan yaşlıların yaşam doyumu puanı 7.90 olarak daha düşük düzeyde saptamıştır. Bu çalışmada yaşlıların 
yaşam doyumu puanı 15.81 olup, Özerin (2001) çalışmasındaki evde yaşayan yaşlılardaki yaşam doyumu sonucu ile benzerlik göstermektedir. Yaşlılarda yalnızlık ve yaşam doyumu ile ilgili yapılan çalışmalarda da; Kapıkaran (2016) şehir, ilçe ve köyde yaşayan 110 yaşlı birey ile yaptığı çalışmada yalnızlıkla yaşam doyumu arasında anlamlı negatif yönlü zayıf bir ilişki olduğunu, Erol vd. (2016) 210 yaşlı bireyle yaptıkları çalışmada köyde yaşayan yaşlıların kentte yaşayanlara göre daha az yalnızlık ve daha fazla yaşam doyumu yaşadıklarını saptamıştır.

Bu çalışmada yaşlıların orta düzeyde ölüm kaygısı yaşadığı, yaşlıda yalnızlık ve yaşam doyumu düzeyi arttıkça ölüm kaygısının azaldığı belirlenmiştir. Ölüm kaygısının yaşamın sonu ile ilgili düşünce, duygu ve korkulardan oluştuğu, ölüm kaygısının benlik bütünlüğü, ruhsal ve fiziksel zorluklar, sosyokültürel etkenler, yaş, cinsiyet, yaşam düzeni, dini inanç ve gelişimsel süreçten etkilendiği belirtilmektedir (Öztürk, Karakuş veTamam, 2011; Azeem ve Naz, 2015). Yapılan çalışmalarda; Azeem ve Naz (2015) kurumda yaşayan yaşlılarda ölüm kaygısının evde yaşayan yaşlılardan daha fazla olduğunu, Üstüner Top vd. (2010) huzurevinde yaşayan yaşlıların \%51.9'unun orta düzeyde ve \%42'sinin ağır düzeyde ölüm korkusu yaşadığı saptanmıştır. Çalışmalardan elde edilen sonuçlar evde yaşayan yaşl1llarda ölüm kaygısının daha düşük olduğunu göstermektedir. Ayrıca yaşın ilerlemesiyle ortaya çıkan olgunluk ile ölümü kabullenmenin gerçekleştiği ve ölüm kaygısının azaldığı belirtilmektedir (Öztürk vd., 2011). Bizim çalışmamızdaki yaşlı bireylerde yalnızlık ve yaşam doyumu arttıkça ölüm kaygısının azalması sonucunda; yaşlıların tanıdığı insanlarla birlikte yaşaması, sosyal destek kaynaklarından yararlanması, yaşl111lığı kabullenmesi ve benlik bütünlüğü gibi faktörlerin etkili olabileceği düşünülmektedir.

Çalışmamızda boşanmış yaşlıların yalnızlık ve yaşam doyumu puanı daha yüksek, ölüm kaygısı puanı daha düşüktür. Yapılan çalışmalarda yaşlılarda medeni durumun yaşam doyumu, yalnızlık ve ölüm kaygısına etkisi ile ilgili farklı sonuçlar saptanmıştır. Bu çalışmalarda; Enkvist, Ekström, ve Elmstahl (2012) medeni durumun yaşlılarda yaşam doyumunu anlamlı düzeyde etkilediğini, Kankaya ve Karadakovan (2017) yaşlı bireylerde medeni durumun yaşam doyumunu anlamlı düzeyde etkilemediğini, Erol vd. (2016) yaşlıların medeni durumu ile yalnızlık puan ortalamaları arasında anlamlı fark olmadığını, Takagi, Saito ve Chan (2020) yalnız yaşayan veya sadece bir çocuk ile yaşayan yaşlılarda yalnızlık düzeyinin, yalnız eşi ile yaşayan yaşlılara göre daha yüksek olduğunu, Örsal, Yenilmez, Çelik ve Işıklı (2012) yaşlı bireylerde medeni durum ile ölüm kaygısı arasında anlamlı fark olmadığını, Keskin, Dülgerler, Engin, Bilge, Özer ve Peker (2018) yalnız yaşayan yaşlılarda ölüm kaygısının yüksek olduğunu, Öztürk vd. (2011) evli yaşlılarda ölüm kaygı puanının bekar yaşlılardan daha düşük olduğunu belirlemiştir. Bizim çalışmamızdaki boşanmış yaşlılarda yalnızlık ve yaşam doyumunun yüksek, ölüm kaygısının düşük olması sonucunda; boşanma durumu genelikle yaşamın yaşl11ık öncesi dönemlerinde gerçekleştiği için bireyin boşanma sonrası yaşamına uyum sağlayarak yaşl11ık dönemine ulaşması, evlilikte yaşanan stresörlerin ve sorunların boşanma ile ilgili ortadan kalkması, bireyin yaşamını düzenleme sorumluluğunu tek başına üstlenmesi gibi faktörlerin etkili olabileceği düşünülmektedir.

Çalışmada eğitim durumuna göre yaşı bireylerin yaşam doyumunda anlamlı fark olmadığı ancak lise eğitimli yaşlılarda yalnızlık puanının daha yüksek, ölüm kaygısı puanının daha düşük olduğu belirlenmiştir. Kapıkıran (2016) evde yaşayan yaşlılarda eğitim düzeyine göre yaşam doyumu bakımından anlamlı bir fark olmadığını, bununla birlikte eğitim düzey ile yalnızlık bakımdan anlamlı düzeyde fark olduğunu, ortaokul ve lise düzeyinde olanlarda yalnızlığın daha yüksek olduğunu saptamıştır. Çalışma bulgusu bu sonuçla uyumludur. Bazı çalışmalarda da farklı sonuçlara ulaşılmıştır. Erol vd. (2016) yaşlıların eğitim durumu ile yalnızlık puan ortalamaları arasında anlamlı bir fark olmadığını, Routasalo ve Pitkala (2003) yaşlılarda eğitim düzeyi düştükçe yalnızlığın arttığını bulmuştur. $\mathrm{Bu}$ çalışmada lise eğitimli yaşlılarda ölüm kaygısı puanı düşüktür. Öztürk vd. (2011) yaşlılarda eğitim süresi ile ölüm kaygısı arasında anlamlı negatif bir ilişki olduğunu belirlemiştir. Ayrıca çalışma alanı ve gündelik yaşamdaki yoğunluğun ölümü hatırlama düzeyini düşürebileceği vurgulanmaktadır (Örsal vd., 2012).

Çalışmada yaşlıların sadece \%11.9'unun yakın akrabası ile yaşadığı, bu yaşlıların yalnızlık ve yaşam doyumu puanının daha yüksek, ölüm kaygısı puanının daha düşük olduğu saptanmıştır. Yaşlılık döneminde bireyler genellikle eş kaybı ve çocukların iş nedeni ile uzakta olması gibi nedenler ile yalnız tek başına veya yakın akrabaları ile birlikte yaşamak zorunda kalmaktadır. Yapılan çalışmalarda; evde 
eşiyle ve çocuklarıyla birlikte yaşayan yaşlıların daha az yalnızlık duygusu yaşadıkları (Parlar Kılıç vd., 2014), evde yalnız yaşayan yaşlıların daha fazla yalnızlık sorunu yaşadığı (Ağırman vd., 2017; Kalınkara ve Sarı, 2019) eşi ile birlikte yaşayan yaşlıların yaşam doyumu puanın daha yüksek olduğu (Kapıkıran, 2016) saptanmıştır. Bu çalışmada diğer çalışmalardan farklı olarak eşi veya çocukları ile birlikte yaşayan yaşlılarda yalnızlık, yaşam doyumu ve ölüm kaygısı puanları arasında anlamlı bir fark saptanmamıştır. $\mathrm{Bu}$ bulgu araştırma sonuçları ile uyumlu değildir. Çalışmamızda ailesi olmadığı için yakın akrabası ile yaşayan yaşlılarda yalnızlık ve yaşam doyumu puanının daha yüksek, ölüm kaygısı puanının daha düşük olması sonucunda; yakın akrabaların yaşı ıirey ile ilişkileri ve sosyal destek kaynağı özelliklerinin etkili olduğu düşünülmektedir. Sosyal desteğin yalnızlık ve yaşam doyumunda önemli bir yordayıcı olduğu, sosyal destek durumunun özellikle sosyal ilişki ağının nicelik ve niteliğinin etkili olduğu belirtilmektedir (Kapıkıran, 2016).

\section{SONUÇ}

Evde yaşayan yaşlılarda yalnızlık, yaşam doyumu ve ölüm kaygısının belirlenmesi amacı ile yapılan bu çalışmada; yaşlılarda yalnızlık, yaşam doyumu ve ölüm kaygısı arasında bir ilişki olduğu, boşanmış, lise eğitimli ve yakın akrabası ile yaşayan yaşlılarda yalnızlık ve yaşam doyumu puanının daha yüksek ölüm kaygısı puanının daha düşük olduğu belirlenmiştir. Elde edilen sonuçlar doğrultusunda;

-Yaşlılara fizik sağlığı kadar ruh sağlı̆̆ını da dikkate alarak biyopsikososyal bütünlük içinde hizmet verilmesi,

-Yaşlı ruh sağlığını koruma ve sürdürmeye yönelik değerlendirme ve planlamaların yapılması,

-Yaşıının yalnızlık duygusu ve yalnızlık düzeyinin azaltılması için komşu, akraba ve diğer sosyal ilişkilerinin artırılması,

-Evde yaşayan yaşl1ların gücü ölçüsünde ve güvenli şekilde ev dışında etkileşimini artıracak, yaşam doyumunu destekleyecek aktivitelere yönlendirilmesi,

-Yaşılıarın sosyal destek kaynakları tespit edilerek, yaşlıların sosyal destek kaynaklarını tanıması ve etkin kullanmasinın desteklenmesi,

-Yaşl11ık dönemi ve yaşlı bireyin gereksinimleri konusunda kamu spotu ve eğitimler aracıllı̆ı ile toplumsal farkındalığın artırılması

-Yerel yönetimlerin işbirliği ile yaşlının yalnız kalmasını ve yalnız hissetmesini önlemeye yönelik hizmet planlaması ve çevre düzenlemesi yapılması,

-Yaşlılarda yalnızlık, yaşam doyumu ve ölüm kaygısı ile ilgili nitel çalışmaların yapılması önerilmiştir.

Bilgilendirme / Acknowledgement:

1- Çalışmaya katılan tüm yaşlılara özellikle teșekkür ediyoruz.

2- Yazarların araştırma tasarımı, veri toplama, veri analizi, makalenin ilk taslağını yazma, makaleyi dergiye sunma gibi katkıları vardır. HT'nin araştırma tasarımı, makale yazma, makaleyi dergiye sunması gibi katkıları vardır. Tüm yazarlar makaleye katkıda bulundular ve makaleyi eleştirel bir bakış açısıyla incelediler. Nihai makale tüm yazarlar tarafindan onaylanmıştır.

3- Makalenin yazarları arasında çıkar çatışması bulunmamaktadır.

4- Bu makalede araştırma ve yayın etiğine uyulmuştur.

5- Çalışmadaki veriler 27 Mayıs - 27 Haziran 2016 tarihleri arasında toplanmıştır.

\section{KAYNAKÇA}

Ağırman, E., Gençer, M. Z., Arıca, S., Kaya, E. ve Eğici, M. T. (2017). Huzurevinde, evde ailesiyle ve yalnız yaşayan yaşlı bireylerde depresyon, yalnızlık hissi düzeylerinin karşılaştırılması. $J$ Contemp Med, 7(3), 234-240.

Akgül, H. ve Yeşilyaprak, B. (2015). Yaşlılar için yalnızlık ölçeğinin Türk kültürüne uyarlaması: Geçerlilik ve güvenirlik çalışması. Yaşlı Sorunları Araştırma Dergisi, (1), 34-45.

Akgül, H. ve Yeşilyaprak, B. (2018). Yalnızlığı azaltma psiko-eğitim programının yaşlıların yalnızlık düzeyine etkisi. Uluslararası Toplum Araştırmaları Dergisi, 8(14), 11-51. 
Azeem, F. ve Naz, M. A. (2015). Resilience, death anxiety, and depression among institutionalized and noninstitutionalized elderly. Pakistan Journal of Psychological Research, 30(1), 111-130.

Başterzi, A. D. ve Ertekin Yazıc1, A. (2005). Yaşamın son yılları. Türkiye Klinikleri Journal of Internal Medical Sciences, 1(27), 50-53.

Boylu, A. A. ve Günay, G. (2018). Yaşlı bireylerde algılanan sosyal desteğin yaşam doyumu üzerine etkisi. Insan ve Toplum Bilimleri Araştırma Dergisi, 7(2), 1351-1363.

Çam, C., Atay, E. ve Işık, B. (2018). Yaşl1larda yalnızlık ve yaşam kalitesi. Türk Dünyası Uygulama ve Araştırma Merkezi Halk Sağllğg Dergisi, 3(2), 50-67.

Çevik Akyıl, R., Adıbelli, D., Erdem, N., Kırağ, N., Aktaş, B. ve Karadakovan, A. (2018). Huzurevinde ve evde kalan yaşlılarda yalnızlık ve algılanan sosyal destek ile mutluluk düzeyleri arasındaki ilişki. Anadolu Hemşirelik ve Sağlık Bilimleri Dergisi, 21(1), 33-41.

de Jong Gierveld, J. and Kamphuis, F. H. (1985). The development of a Rasch-type loneliness-scale. Applied Psychological Measurement, 9, 289-299.

Diener, E., Emmons, R. L. ve Griffin, S. (1985). The satisfaction with life scale. J Pers Assess, 49(1), 71-75.

Engin, E., Uğuryol, M. ve Kaçmaz, E. D. (2016). Yalnızlık kavramı ve sağlıklı yaşam üzerine etkileri: gözden geçirme. Uluslararası Sosyal Araştırmalar Dergisi, 9(42), 1101-105.

Enkvist, A., Ekström, H. and Elmstahl, S. (2012). What factors affect Life Satisfaction (LS) among the oldest-old? Archives of Gerontology and Geriatric, 54, 140-145.

Erol, S., Sezer, A., Şişman, F. N. ve Öztürk, S. (2016). Yaşlılarda yalnızlık algııı ve yaşam doyumu. Gümüşhane Üniversitesi Sağlık Bilimleri Dergisi, 5(3), 60-69.

Genç, Y. ve Dalkılıç, P. (2013). Yaşlıların sosyal dışlanma sendromu ve toplumsal beklentileri. International Journal of Social Science, 6(4), 461-482.

Kalınkara, V. ve Sarı, İ. (2019). Yaşlılarda sosyal ağ kullanımı ve yalnızlık ilişkisinin belirlenmesi. Yaşlı Sorunları Araştırma Dergisi, 12(1), 8-19.

Kankaya, H. ve Karadakovan, A. (2017). Yaşlı bireylerde günlük yaşam aktivite düzeylerinin yaşam kalitesi ve yaşam doyumuna etkisi. Gümüşhane Üniversitesi Sağlık Bilimleri, 6(4), 21-29.

Kapıkıran, Ş. (2016). Yaşlılarda yalnızlık ile yaşam doyumu arasındaki ilişki: Sosyal desteğin aracılık rolünün sınanması. Yaşlı Sorunları Araştırma Dergisi, 9, 13-25.

Karahan, F. Ş. ve Hamarta, E. (2019). Geriatrik olgularda kronik hastalıkların ve polifarmasinin ölüm kaygıs1 ve anksiyete üzerine etkisi. Aegean J Med Sci, 1, 8-13.

Keskin, G., Dülgerler, Ş., Engin, E., Bilge, A., Özer, S. ve Peker, S. (2018). Yaşl1larda ölüm anksiyetesi: Günlük yaşama katılımları ile ilişkisi. Turkish Journal of Geriatrics, 21(3), 383393.

Khademi, M. J., Rashedi, V., Sajadi, S. and Gheshlaghi, S. M. (2015). Anxiety and loneliness in the Iranian older adults. International Journal of Psychology and Behavioral Sciences, 5(2), 4952.

Meléndez, J. C., Tomás, J. M., Oliver, A. and Navarro, E. (2009). Psychological and physical dimensions explaining life satisfaction among the elderly: A structural model examination. Archives of Gerontology and Geriatrics, 48(3), 291-295.

Örsal, Ö., Yenilmez, Ç., Çelik, N. ve Işıklı, B. (2012). Huzurevinde ve evinde yaşayan yaşl1larda ölüm anksiyetesi ve sosyal destek arasındaki ilişki. Turkish Journal of Geriatrics, 15(3), 332-338.

Özer, M. (2001). Huzurevinde ve aile ortamında yaşayan yaşlıların öz bakım gücü ve yaşam doyumunun incelenmesi. Yayınlanmamış doktora tezi, Ege Üniversitesi, İzmir. 
Öztürk, Z., Karakuş, G. ve Tamam, L. (2011). Yaşlı bireylerde ölüm kaygısı. Anadolu Psikiyatri Dergisi, 12(1), 37-43.

Parlar Kılıç, S., Karadăg, G., Koçak, H. S. ve Korhan, E. A. (2014). Evde yaşayan yaşlıların yalnızlık ve depresyon düzeyleri ile yaşlılık algılarının incelenmesi. Turkish Journal of Geriatrics, 17(1), 70-76.

Recepoğlu, E. (2013). Analyzing the relationship between prospective teachers 'life satisfaction and attitudes concerning teaching profession. H.U. Journal of Education, 1, 311-326.

Routasalo, P. and Pitkala, K. H. (2003). Loneliness among older people. Reviews in Clinical Gerontology, 13(4), 303-311.

Rowe, J. W. and Kahn, R. L. (2015). Successful aging 2.0: Conceptual expansions for the 21st century. Journal of Gerontology, Psychological Science, 70(4), 593-598.

Sayın Kasar, K., Karaman, E., Say Şahin, D., Yıldırım, Y. ve Şenuzun Aykar, F. (2016). Yaşlı bireylerin yaşadıkları ölüm kaygısı ile yaşam kalitesi arasındaki ilişki. Gümüşhane Üniversitesi Sağllk Bilimleri Dergisi, 5(2), 48-55.

Softa, H. K., Karaahmetoğlu, G. U., Erdoğan, O. ve Yavuz, S. (2015). Yaşlilarda yaşam doyumunu etkileyen bazı faktörlerin incelenmesi. Yaşlı Sorunları Araştırma Dergisi, (1), 12-21.

Şenol, C. (1989). Ankara ilinde kurumlarda yaşayan yaşlılarda ölüme ilişkin kaygı ve korkular. Yayınlanmamış yüksek lisans tezi, Ankara Üniversitesi, Ankara.

Şimşek, N., Küçük Öztürk, G. ve Yüceler Kaçmaz, H. (2018). Yaşlılık ve yalnızlık. Uluslararası Sosyal Araştırmalar Dergisi, 11(58), 496-499.

Takagi, E., Saito, Y. and Chan, A. (2020). Gender differences in the association between social relationships and loneliness among older adults in Singapore. Journal of Population Research. https://doi.org/10.1007/s12546-020-09242-0

Templer, D. I. (1970). The construction and validation of a death anxiety scale. The Journal of General Psychology, 82(2), 165-177.

Türkiye İstatistik Kurumu (TÜİK). Adrese dayalı nüfus kayıt sistemi sonuçları, 2019. 17 Temmuz 2020 tarihinde http://www.tuik.gov.tr/HbGetirHTML.do?id=33705 adresinden erişildi.

Türkiye İstatistik Kurumu (TÜIK). İstatistiklerle yaşl1lar, 2018. 5 Nisan 2020 tarihinde http://www.tuik.gov.tr/PreHaberBultenleri.do?id=30699 adresinden erişildi.

Üstüner Top, F., Saraç, A. ve Yaşar, G. (2010). Huzurevinde yaşayan bireylerde depresyon düzeyi, ölüm kaygısı ve günlük yaşam işlevlerinin belirlenmesi. Klinik Psikiyatri, 13, 14-22.

Yetim, Ü. (1993). Life satisfaction: A study based on the organization of personal projects. Social Indicators Research, 29(3), 277-289.

Zhang, J., Peng, J., Gao, P., Huang, H., Cao, Y., Zheng, L. and Miao, D. (2019). Relationship between meaning in life and death anxiety in the elderly: Self-esteem as a mediator. BMC Geriatrics, 19,308 . 